\section{El consumo cultural en Cuba y sus nexos con la ciudadanía. Posibilidades desde entornos periféricos}

\section{Cultural consumption in Cuba and its links with citizenship. Possibilities from peripheral environments}

https://doi.org/10.18566/comunica.n44.a08

Recibido: 27 de febrero de 2021

Aceptado: 30 de abril de 2021

\section{Resumen}

Este artículo parte de una revisión de los estudios sobre consumo cultural en Cuba para conectar ese estado del arte con otros estudios y perspectivas sobre consumo cultural, industrias, bienes culturales y medios masivos de comunicación que podrían enriquecerfuturasaproximaciones, especialmente al abordar el mercado alternativo de producción y distribución de contenidos de entretenimiento por vías informales. Finalmente, se proyectan posibles escenarios que podrían derivarse de los entornos periféricos de producción, distribución y consumo de contenidos, y se analizan sus potencialidades poniendo en un lugar central los nexos entre el consumo de entretenimiento y la experiencia de la ciudadanía.

El trabajo, de tipo analítico, se apoyó en la revisión bibliográfica y documental y el soporte teórico parte de la economía política de la comunicación, desde una posición liminal con los estudios culturales y la ciencia política. El interés de esta perspectiva interdisciplinaria es pensar las implicaciones del consumo cultural informal en la conformación de la ciudadanía, entendiendo que ser ciudadano no tiene que ver exclusivamente con los derechos reconocidos por el Estado, sino además con las prácticas culturales.

Entre las reflexiones finales destaca que, aunque el origen del paquete es mercantil, puede cambiar en sus usos y en los resultados alternos que de estos se derivan; por ejemplo, procesos de sociabilidad en el contexto físico
Comunicación

número 44

Enero - junio

2021 | pp. 122-138

\section{Cosette Celecia Pérez}

Doctora en Estudios

Socioculturales, maestra en

Estudios de la Cultura y la

Comunicación y licenciada

en Periodismo. Actualmente

es becaria del Programa

de Becas Posdoctorales

en la Universidad Nacional

Autónoma de México

(UNAM), en el Centro

de Investigaciones

Interdisciplinarias en

Ciencias y Humanidades.

País: México

cosettecelecia@gmail.com http: / / orcid.org/0000-00022469-9317 
y virtual; espacios de libertad desde el consumo que podrían repercutir en otros entornos; reflexividad acerca de la autonomía individual; inserción en los flujos globales de consumo cultural; diversificación de referentes; e incorporación de prácticas para reproducir y compartir medios digitales.

\section{Abstract}

This article is based on a review of studies on cultural consumption in Cuba to connect this state of the art with other studies and perspectives on cultural consumption, industries, cultural goods and mass media that could enrich future approaches, especially when addressing the alternative market of production and distribution of entertainment content through informal channels. Finally, possible scenarios that could arise from the peripheral environments of production, distribution and consumption of content are projected and their potentialities are analyzed, placing in a central place the links between the consumption of entertainment and the experience of the citizenry.

The work, of an analytical nature, was supported by the literature and documentary review and the theoretical support was based on the Political Economy of Communication, from a liminal position with Cultural Studies and Political Science. The interest of this interdisciplinary perspective is to think about the implications of informal cultural consumption in the shaping of citizenship, understanding that being a citizen does not only have to do with the rights recognized by the State, but also with cultural practices.

Among the final reflections, it stands out that, although the origin of the package is mercantile, it can change in its uses and in the alternative results that derive from them, for example: processes of sociability in the physical and virtual context; spaces of freedom from consumption that could have repercussions in other environments; reflexivity about individual autonomy; insertion in the global flows of cultural consumption; diversification of references; and incorporation of practices to reproduce and share digital media.

\section{Introducción}

El rol de la cultura en el desarrollo y el cambio social y la importancia de las industrias culturales en las economías confirman la necesidad de atender los temas culturales desde una perspectiva interdisciplinaria que reconozca sus dimensiones simbólica y económica. En este trabajo interesa revisar los abordajes en torno al consumo cultural en Cuba para sistematizar cuáles han sido las perspectivas privilegiadas al tratar este tema y evaluar el desplazamiento de la atención de la academia de los entornos

\section{Palabras clave}

Consumo cultural, ciudadanía, Cuba, industrias culturales, consumo informal, economía política de la comunicación, estudios culturales.

\section{Key words}

Cultural consumption, citizenship, Cuba, cultural industries, informal consumption, Political Economy of Communication, Cultural Studies. 
institucionalizados de producción y distribución de contenidos culturales a los ámbitos informales. Este repaso crítico se centra en los estudios sobre consumo de entretenimiento audiovisual, por su preeminencia dentro del consumo cultural en Cuba, y se interesa particularmente por los abordajes sobre la producción, distribución y consumo de contenidos offline, especialmente por el compendio conocido como el "paquete semanal".

Vincent Mosco (2006) señala que la economía política de la comunicación (EPC) ha destacado "por su énfasis en describir y examinar el significado de las instituciones, especialmente empresas y gobiernos, responsables por la producción, distribución e intercambio de las mercancías de comunicación y por la regulación del mercado de comunicación" (2006, p. 67). Pero resulta pertinente atender también desde la EPC a fenómenos comunicativos desregulados, como las industrias culturales informales que, aun desde fuera de las estructuras formalizadas, participan de los procesos sociales. Atendiendo a esto es preciso recuperar lo que Mosco (2006) denomina una "renovada economía política de la comunicación" que adopte una posición liminal con los estudios culturales y la ciencia política.

Este artículo realiza una revisión de las investigaciones sobre consumo cultural en cuba para conectar esos hallazgos con otros estudios y perspectivas sobre consumo cultural, industrias, bienes culturales y medios masivos de comunicación que podrían enriquecer futuras aproximaciones, especialmente al abordar el mercado alternativo de producción y distribución de contenidos de entretenimiento por vías informales. Finalmente, se proyectan posibles escenarios que podrían derivarse de estos entornos informales de producción, distribución y consumo de contenidos, y se analizan sus potencialidades poniendo en un lugar central los nexos entre el consumo de entretenimiento y la experiencia de la ciudadanía.

\section{Abordajes al consumo cultural: de los entornos institucionales a los periféricos}

Los estudios sobre EPC son un área poco (re)visitada por la academia cubana, pero desde ahí recuperamos un conjunto de tres tesis de licenciatura de la Facultad de Comunicación de la Universidad de La Habana que abordan los medios estatales como industrias culturales. Este proyecto incluyó investigaciones sobre la televisión nacional (Durán, 2015), tres emisoras del Sistema Nacional de Radio (Garcés, 2015) y el Instituto Cubano del Arte e Industria Cinematográficos (Oro, 2015). En todos los casos se trató de estudios cualitativos de carácter exploratorio. Generados en esta misma institución y también con la EPC como soporte teórico, se encuentra un estudio sobre comunicación popular en Cuba (Díaz, 2014) y otro sobre la 
industria de eventos dentro del sector turístico como industria cultural en Cuba y Colombia (Martínez, 2015).

El Instituto Cubano de Investigación Cultural Juan Marinello posee un grupo de trabajo sobre economía política de la cultura en el cual resalta el quehacer de Tania García (2018), quien ha abordado el papel de la cultura en Cuba como promotora de desarrollo. Su trabajo destaca la función de la cultura como espacio para reproducir los valores del socialismo, de modo que se centra en la cultura generada desde entornos institucionales y afines al proyecto político gubernamental. También desde ese instituto, Yanet Martínez enfatiza la articulación de la televisión cubana con las políticas diseñadas por el Estado. La autora explica, al referirse a la labor de la televisión nacional, que su programación busca "lograr ciertos objetivos que forman parte del modelo cultural hegemónico cubano" (Martínez, 2008, p. 6).

Un elemento visible en el estudio de las industrias culturales cubanas desde la academia del país es la legitimación del paternalismo que caracteriza a la política cultural de la isla, realidad que lejos de cuestionarse se reproduce como parte de un escenario normalizado. Desde estas perspectivas, el auge de las industrias culturales a partir de la emergencia de nuevos medios y plataformas digitales aparece como una amenaza que podría corromper una idea de la cultura defendida por el Estado, a través de la cual busca "preservar su política cultural en función de la educación formadora de su pueblo y protección de la identidad nacional como primeros objetivos", si bien se reconocen "las potencialidades que brinda la comercialización de las mercancías culturales para la economía” (Oro, 2015, pp. 2-3).

Desde una perspectiva teórica, Jorge Carballo y Janet Rojas (2019) exploran el tema del emprendimiento cultural como factor de reconfiguración territorial. Su trabajo destaca los beneficios de la gestión articulada entre instituciones y empresarios de las artes y la cultura y la importancia del enfoque espacial en los estudios sobre el tema. Mientras Jaqueline Laguardia (2012b) problematiza el empleo de los conceptos "industrias culturales" e "industrias creativas", partiendo de sus orígenes epistemológicos y señalando sus implicaciones políticas en un contexto de globalización neoliberal. La autora defiende la pertinencia del primer término, en tanto argumenta que el segundo pretende ignorar la racionalidad del capital en la cultura.

Laguardia (2012a) define a los bienes culturales como aquellos...

... bienes económicos que tienen como materia prima una creación con alto valor simbólico, vertida en soportes materiales de diversa índole y generalmente protegida legalmente a favor de su autor, destinados a promover, o satisfacer, demandas de contenidos simbólicos (2012a, p. 136). 
Esta definición, que condensa aportaciones teóricas de la EPC y de los estudios culturales, ofrece una pauta acerca del modo en que se han entendido los bienes culturales y también las industrias que los generan como elementos que funcionan y se producen dentro de los entornos institucionales y regulados de las sociedades. Esto evidencia la necesidad de ampliar y flexibilizar las formulaciones sobre estos términos, de modo que puedan considerarse también los entornos periféricos, no legales, donde se producen y distribuyen contenidos, y analizar de manera situada el lugar que ocupan en la sociedad, tanto en términos económicos como simbólicos, máxime considerando que estas ofertas alimentan un mercado informal generado por demandas no cubiertas por las instituciones.

Un estudio de 2003 sobre consumo cultural en Cuba señala los altos niveles de consumo de televisión (87,5 \%) entre las actividades principales desarrolladas en el país, lo que indica, además, una homogeneización en cuanto al consumo cultural (Linares et al., 2003, citados por Martínez, 2008). Esta característica ha sido un nicho propicio para la circulación subterránea de contenidos de entretenimiento y la demanda del compendio conocido como el paquete semanal. La emergencia de estos espacios no legales en Cuba se relaciona con la innovación tecnológica y con las demandas de consumo cultural de amplios grupos no satisfechas por los medios estatales.

Los públicos encuentran creativas formas de sortear las limitaciones económicas tanto como las escasas ofertas estatales para acceder a contenidos de su interés por vías alternativas. Los mercados informales y la piratería se convierten en opciones de acceso e incluso de supervivencia económica en esos casos, y su relevancia en la vida cotidiana de ciertos grupos obliga a pensarlos de manera situada. Tal y como lo explica Ramón Lobato (2012), quien mantiene una postura flexible acerca de la piratería, "en su forma más pura, la economía informal es un espacio ajeno a la medición, la fiscalización y la regulación”. Según el contexto, "la piratería puede verse como robo o negocio legítimo, libertad de expresión o una forma de resistencia política. A veces, puede ser todas estas cosas a la vez" (Lobato, 2012, p. 70).

La piratería es una forma de acceso en contextos donde los contenidos culturales no están disponibles legalmente. Este tipo de piratería no es un acto de autoconciencia política, sino una actividad banal y cotidiana practicada en contextos donde las alternativas legales no existen (Lobato, 2012, p. 82).

Dentro de los abordajes a la producción, circulación y consumo de contenidos por vías informales en Cuba destacan los trabajos dedicados al "paquete semanal"1 (Barrera, 2009; Fonseca y Castañeda, 2015; Ramos, 2016; Concepción, 2015; Cabrera, 2015; Pertierra, 2011, 2012; Celecia, 2019; Rodríguez, 2019), los
1 "El paquete" o "paquete semanal" es un compendio de contenidos cuya circulación offline es una adaptación al contexto de desconexión que existe en Cuba y una opción de consumo informal frente a la programación estatal. Sobre este compendio y su relación con el periodismo independiente volveremos más adelante en este artículo. 
cuales coinciden en señalar una creciente preferencia del consumo informal sobre el estatal. Estos análisis atienden a los cambios generados a partir de la actualización del modelo socioeconómico cubano y el modo en que estos han incidido en la transformación del entorno mediático. Sus marcos teóricos se apoyan en los estudios críticos latinoamericanos y apelan a las nociones de industrias culturales y economías informales. El estado del arte sobre este tema abarca fundamentalmente estudios exploratorios, de modo que es necesario sumar revisiones analíticas y teóricas que aporten nuevos elementos para seguir comprendiendo las dinámicas que se generan desde los procesos de producción, distribución y consumo del paquete semanal.

El paquete es un compendio de aproximadamente un terabyte de materiales descargados de internet o pirateados de canales extranjeros. Circula de mano en mano desde 2010 por dispositivos de almacenamiento externo y resulta una evolución de anteriores formas de distribución clandestina de contenidos en el país. Aunque puede obtenerse gratuitamente a través de redes de relaciones que median su circulación, es un producto que surge y se mantiene con fines comerciales. Su circulación es ilegal pero tolerada. Incluye películas, reality shows, programas humorísticos y musicales, y otro tipo de programas de canales fundamentalmente estadounidenses, series y documentales de procedencia variada, además de telenovelas, sobre todo latinoamericanas. También funciona como tienda offline de aplicaciones, videojuegos y actualizaciones de antivirus.

Este producto, al mismo tiempo proceso y negocio, emula a una plataforma de streaming adaptada al contexto de desconexión cubano y se apoya en una eficiente red de distribución de mano en mano. El paquete puede ser considerado una industria cultural informal, ya que en su estructura organizativa son distinguibles diferentes niveles y roles, y posee una parrilla de programación amplia, constante y variada, con contenidos incluso originalmente concebidos para este formato; todo esto genera una vasta red de gestión y, por tanto, de empleos informales.

Resalta, además, la capacidad de las matrices productoras del compendio de gestionar los contenidos y activar la red desde arriba, así como de concentrar buena parte de las ganancias que genera el negocio, lo que las convierte en el núcleo de esta industria informal. Asimismo, el paquete ha creado sus propios códigos culturales y varios autores que han estudiado su funcionamiento aseguran que se ha convertido en el mayor empleador privado del país (Fazekas y Marshall, 2016; Dye et al., 2018), otro elemento que refuerza su carácter de industria cultural informal.

Néstor García Canclini (2002) define a las industrias culturales como el conjunto de actividades de producción, comercialización y comunicación 
en gran escala de mensajes y bienes culturales que favorecen la difusión masiva, nacional e internacional, de la información y el entretenimiento, y el acceso creciente de las mayorías. Catalogar al "paquete como industria cultural informal" pone de relieve que se vincula a la producción y el intercambio económicos fuera del ámbito del Estado, de modo que su gestión tiene lugar en un mercado al margen de las instituciones estatales y sus regulaciones de circulación de contenido.

\section{Brújulas teórico-conceptuales: EPC y estudios culturales latinoamericanos}

Siguiendo la tradición marxista y sus explicaciones sobre el funcionamiento del sistema capitalista de producción, surge una corriente de pensamiento que aplica la economía política al ámbito de la comunicación para analizar cómo intervienen las relaciones de producción en la creación, distribución y consumo de bienes simbólicos a través de los medios de comunicación masiva. La economía política de la comunicación (EPC) constituye una corriente de pensamiento de carácter interdisciplinar que integra referentes críticos del pensamiento político, económico, comunicativo y cultural.

En relación con la EPC, el estudio de las industrias culturales ha tenido gran importancia para el análisis crítico de la comunicación. El concepto industria cultural en singular es planteado a mediados de los años 40 del siglo pasado por los teóricos marxistas de la Escuela de Frankfurt Theodor Adorno y Max Horkheimer al analizar cómo la cultura se inserta en los ciclos de reproducción y legitimación del modo de producción capitalista. Esto, según sus concepciones, tributaba a generar masas conformistas y acríticas, consumidoras de productos culturales producidos en serie. Mientras en plural y alejado del pesimismo y elitismo frankfurtianos, García Canclini, vuelto hacia las realidades latinoamericanas, define a las industrias culturales como "el conjunto de actividades de producción, comercialización y comunicación en gran escala de mensajes y bienes culturales que favorecen la difusión masiva, nacional e internacional, de la información y el entretenimiento" (2002, p. 1).

Con el siglo XXI y los cambios provocados por las nuevas tecnologías se produce una revitalización de los estudios desde la EPC, que tienen como centro la crítica a los grandes medios de comunicación y las afectaciones a la pluralidad y diversidad en los contenidos. En la actualidad, los cambios en la propiedad de las industrias culturales y mediáticas y las consecuencias derivadas de ello pueden identificarse con bastante facilidad; sin embargo, las consecuencias que genera su producción simbólica son más complejas de analizar (Miège, 2006; Sánchez, 2006), y es en este punto en el que se centra nuestro interés con relación al consumo del paquete semanal en Cuba. 
Tradicionalmente, la EPC se ha concentrado en explicar el quehacer de los medios de comunicación y la cultura en las sociedades capitalistas, y menos dentro de otros regímenes sociales. Graham Murdock, en su trascendental polémica con Dallas Smythe, le señala precisamente que en sus análisis solo toma en cuenta a las sociedades capitalistas avanzadas y no considera a los Estados socialistas, enfatizando que es necesario un estudio real de aquellas formas de sociedad que han surgido de las revoluciones inspiradas por el mismo marxismo (Murdock, 2006a, 2006b).

Si en contextos capitalistas unas pocas empresas determinan la estructura, organización y naturaleza de los contenidos que circulan, en el caso cubano esas capacidades están a cargo del Estado. Si la concentración elimina la competencia y con ella se suprime la pluralidad, algo similar sucede con el monopolio estatal sobre lo público. Pero tanto la concentración del capital como la estatización de la comunicación ven emerger alternativas dentro de sus propios predios. En estos últimos casos es preciso redireccionar los enfoques y proponer nuevos abordajes para evaluar quiénes y cómo generan propuestas "alternativas" que permitan comprender y explicar estos contextos, así como desnaturalizar los controles estatales tanto como la asimilación de modelos comunicativos sustentados en principios mercantilistas y poco, sino nada, preocupados por la democratización comunicacional.

Vincent Mosco (2006) identifica tres procesos que constituyen los principales puntos de partida para la investigación en la economía política y que se aplican igualmente al estudio de la EPC: mercantilización, proceso de transformar cosas valoradas por su uso en productos comercializables por lo que de ellos se puede obtener en un intercambio; espacialización, proceso de trascender los límites del espacio geográfico a través de, principalmente, los medios masivos y las tecnologías de la comunicación; y estructuración, proceso de crear relaciones sociales (2006, p. 58).

El proceso de mercantilización implica un doble significado para la investigación en comunicación dado que las prácticas y tecnologías de la comunicación contribuyen al proceso general de mercantilización en toda la sociedad. En el caso del paquete, esto tiene implicaciones en varios niveles de su funcionamiento. Por un lado, sus contenidos incluyen publicidad de negocios particulares, parte de la cual se inserta en las matrices, mientras otra se incluye al llegar a los distribuidores provinciales, quienes incorporan anuncios de negocios locales. De tal modo, el paquete incluye a un tiempo en las prácticas cotidianas de consumo el lenguaje mercantil de la publicidad y la propia práctica del pago por consumo de contenidos de entretenimiento e información. Con esto, la presencia del paquete semanal interviene en el ámbito de las prácticas sociales y de lo simbólico. 
Mosco (2006) aboga por repensar la economía política para enfatizar precisamente el cambio social, los procesos y las relaciones sociales, por encima de la tendencia tradicional en esta área a privilegiar el examen de las estructuras sociales y las instituciones.

Esto significa que la investigación parte de la perspectiva de que el cambio social es ubicuo, que las estructuras e instituciones están cambiando permanentemente, y que por lo tanto es más útil desarrollar puntos de partida que caractericen procesos que simplemente identificar instituciones relevantes (2006, p. 66).

Esta propuesta se adecúa a las necesidades teóricas y metodológicas para atender un caso como el del consumo cultural por vías informales en Cuba. Además, atender este fenómeno desde la perspectiva de las industrias culturales implica comprender el funcionamiento de sus lógicas de producción y los ámbitos sobre los que estas intervienen: estructura empresarial, competencia comunicativa y competitividad económica (Martín-Barbero, 2003).

En cuanto al primer ámbito, el paquete tiene una clara estructura piramidal cuya cúspide está constituida por las matrices que controlan a descargadores y distribuidores y que se encargan de la edición y adición de contenidos; cuenta también con una robusta red de distribución, parte de la cual se autoorganiza fuera de la estructura del negocio. Como industria cultural informal, parte de sus procesos se nutren de la piratería de contenidos, asociada a otras prácticas informales (como el uso de antenas parabólicas ilegales), así como del desvío de recursos estatales y estrategias de aprovechamiento de estructuras institucionales, como el uso de las redes de transporte nacional para trasladar diariamente el paquete a todo el país.

En cuanto a la competencia comunicativa, relacionada con la capacidad de interpelar, construir públicos, audiencias y consumidores, encontramos que el paquete tiene tanto suficientes consumidores que le permiten su rentabilidad como numerosos usuarios-receptores que acceden a sus contenidos de diferentes formas, lo cual garantiza su popularidad y también tributa a su éxito como negocio. Su alcance, independientemente de que muchos lo adquieran de manera gratuita, es relevante para la inserción de publicidad en el paquete. Este servicio constituye una importante fuente de ingresos para las matrices, quienes pueden cobrar el equivalente a entre 100 y 300 dólares estadounidenses por incluir publicidad de negocios locales en las carpetas del compendio. Esto implica que, contrariamente a lo que sucede con los medios estatales, en los que no existe publicidad comercial, los usuarios del paquete se constituyen, como explica Murdock (2006a) y en consonancia con el acontecer global, como consumidores dos 
veces: como audiencia consumidora de bienes y estilos de vida presentes en los contenidos audiovisuales y como compradores potenciales de las mercancías que se anuncian en la publicidad que los acompaña.

También hay que señalar que la interacción de los gestores del paquete con el público, gracias a la propia estructura de la red, es bastante cercana y frecuente y hay evidencia de cómo tanto los vendedores locales como las matrices atienden a las demandas de sus compradores. Ejemplos claros son el hecho de que en las matrices se editen los segmentos de comerciales insertos en la programación pirateada de canales extranjeros, en atención a la demanda de los usuarios de eliminar estas interrupciones, a las que los cubanos no están habituados. Esto también favorece la atención a la publicidad local, que no interfiere directamente en los contenidos, sino que se coloca en carpetas específicas y en algunos casos (con un costo mayor para los anunciantes) se pasa a través de un cintillo en la parte inferior de la imagen en aquellos programas con mayor audiencia, como los humorísticos. Mientras, en el caso de los vendedores locales, se ubican estrategias como eliminar determinados contenidos que saben de antemano no agradan a sus compradores y crear carpetas para comunidades con intereses específicos (otakus, gamers, grupos religiosos, entre otros).

Las estrategias anteriores también se vinculan con el ámbito de la competitividad económica, a lo que habría que sumar la diversificación de contenidos, servicios y la ampliación de la frecuencia de actualización que ha experimentado el paquete en los últimos años. En cuanto a la competencia entre matrices, se da a través de los precios y servicios que cada una ofrece; sin embargo, su propio carácter informal implica que existan formas de enfrentamiento entre matrices relacionadas con el "control de territorios", asunto recurrente en los entornos ilegales.

El estudio de las industrias culturales estatales cubanas muestra que estas resultan instrumentos de legitimación del orden existente, un orden estatal socialista. Se trata de una adaptación por analogía de lo que sucede con las industrias culturales en el capitalismo. Sin embargo, en el caso del paquete debe considerarse tanto su carácter no estatal e informal como sus contenidos, que reproducen fundamentalmente parrillas de medios dominantes foráneos. ¿Es, entonces, el paquete un producto que reproduce lógicas mercantiles en su funcionamiento, pero cuya existencia también cuestiona un orden local, caracterizado por el monopolio estatal sobre los medios e instituciones culturales? ¿Puede al mismo tiempo tratarse de un replicador de la cultura de masas global y un espacio de disrupción en lo local? Para responder a estas preguntas es imprescindible acudir a los estudios culturales latinoamericanos. 


\section{Nexos entre consumo y ciudadanía}

García Canclini (1995) reconoce que tanto la globalización como el mercado y el consumo tienen elementos de cultura.

Es necesario, entonces, ir hacia el núcleo de lo que en la política es relación social: el ejercicio de la ciudadanía. Y sin desvincular esta práctica de las actividades a través de las cuales sentimos que pertenecemos, que formamos parte de redes sociales, en esta época globalizada, o sea ocupándonos del consumo (García, 1995, p. 18).

Coincidimos con este autor en la utilidad de vincular el consumo con la ciudadanía y con la idea de que "hay que deconstruir las concepciones que encuentran los comportamientos de los consumidores predominantemente irracionales y las que sólo ven a los ciudadanos actuando en función de la racionalidad de los principios ideológicos" (García, 1995, pp. 18-19).

Denise Cogo (2011), por su parte, entiende al consumo cultural...

... no sólo abordado en su dimensión de posesiones individuales o de reproducción de las fuerzas económicas, sino también, y principalmente, concebido como producción de sentidos y un espacio de lucha y acción social que forma parte de un conjunto de interacciones socioculturales complejas (2011, p. 4).

Relacionado con estas propuestas encontramos que el paquete semanal permite elacceso de los espectadores cubanos a los contenidos más populares de las industrias culturales globales. Aunque se trata fundamentalmente de entretenimiento, esto impacta en la sociabilidad al poner en circulación temas y códigos que favorecen, por ejemplo, el intercambio de los cubanos de la isla con su diáspora. Asimismo, el paquete ofrece una posibilidad de elección, con espacios de autonomía que no por acotados dejan de ser significativos en el contexto nacional.

Jesús Martín-Barbero (2003) plantea que no puede circunscribirse la cultura de masas a los productos de los medios de comunicación, sino que la cultura que estos promueven también es un espacio estratégico de la lucha de clases, de manera que junto a la lógica comercial que los guía, estos también pasan a formar parte de la transformación social. En relación con esta idea, Mosco (2006) propone partir de nociones de la EPC para estudiar a los productores culturales como primera fase de análisis de la gestación de cambios sociales y pone como ejemplo de esta perspectiva al trabajo de Armand Mattelart y sus aportaciones para entender la comunicación como uno de los recursos principales de resistencia al poder en América Latina (Mosco, 2006). 
En el ámbito de las prácticas, la reflexividad y la (re)significación, hay un importante espacio inexplorado en torno al consumo cultural en Cuba, y particularmente en torno al consumo cultural informal. En este sentido, valdría la pena indagar, por ejemplo, sobre las nociones acerca de la autonomía individual que se generan entre quienes participan de la circulación y consumo del paquete semanal, entendiendo este consumo como espacio de libertad. Al asumir esta perspectiva puede considerarse el consumo como proceso unido a la experiencia de la ciudadanía, integrado a una dinámica de apropiación colectiva de bienes culturales y comunicacionales que pueden llegar a generar acciones políticas (García, 1995; Cogo, 2011), tanto en un sentido tradicional como en uno posmoderno, centrado en el nivel local, las relaciones informales y la política desde una dimensión micro.

En contextos de libertades limitadas, algunos actores construyen espacios en los que reivindicar su autonomía individual a través de prácticas culturales, como el consumo de información y entretenimiento por vías alternativas a las institucionales. Aunque se trata de iniciativas acotadas al ámbito de lo privado, de lo individual y del consumo, estas experiencias permiten a los participantes desarrollar un sentido de la democracia que se experimenta desde las prácticas cotidianas y desde la subjetividad (Players, 2017). Goeffrey Players, por ejemplo, se refiere al contenido político presente en diferentes prácticas que se rebelan contra la manipulación de las necesidades de información y reivindican la libertad personal y la autonomía de los actores frente a las imposiciones del poder en ese entorno (2018). Aquí podemos ubicar las prácticas que implican rechazar los medios tradicionales dominantes, ampliamente desacreditados por sus vínculos con los poderes políticos y económicos y procurar otras fuentes de información.

En el caso cubano, la participación en la producción, distribución y consumo de contenidos alternativos, como los del paquete semanal, leída desde estas perspectivas, nos permite entender estos procesos como parte de un ejercicio de irreverencia a los discursos, los canales y las normas oficiales, al tiempo que representa la reivindicación de la libertad de elección sobre estos ámbitos, dos elementos que confirman cómo el consumo cultural informal en Cuba se vincula con la construcción y el ejercicio de la ciudadanía desde los entornos periféricos. De este modo, los procesos vinculados al paquete se conectan con una noción amplia y flexible de lo político que pone el centro de atención en el nivel de los sentidos, las prácticas y la cultura.

García Canclini (1995) ya analizaba desde hace casi tres décadas cómo los cambios en la forma de consumir modifican el ser ciudadano, dado que esta condición se materializa más en el consumo privado de bienes y de contenidos de los medios masivos que en la participación colectiva en 

democráticas donde se da sentido a las necesidades de representación, pertenencia, información y ejercicio de los derechos (García, 1995). En el caso cubano, el sistema político limita lo que está sujeto a debate y a elección, dejando así al entorno de lo privado un estrecho margen para decidir de modo autónomo sobre qué consumir. Un espacio en el que el paquete se erige como producto que condensa la posibilidad de adquirir un bien y al mismo tiempo de elegir los contenidos que se consumirán.

Cuando se reconoce que al consumir también se piensa, se elige y reelabora el sentido social hay que analizar cómo interviene esta área de apropiación de bienes y signos en formas más activas de participación que las que habitualmente se ubican bajo el rótulo de consumo. En otros términos, debemos preguntarnos si al consumir no estamos haciendo algo que sustenta, nutre y hasta cierto punto constituye un nuevo modo de ser ciudadanos.

Si la respuesta es positiva, será preciso aceptar que el espacio público desborda ahora la esfera de las interacciones políticas clásicas (García, 1995, p. 27).

Al repensar la ciudadanía en conexión con el consumo, García Canclini (1995) plantea que deben considerarse conjuntamente las actividades del consumo cultural que configuran una dimensión de la ciudadanía. En nuestro caso encontramos que el consumo del paquete se conecta con elementos del ejercicio ciudadano, como el derecho a la información.

\section{Reflexiones finales}

Mientras en el contexto internacional imperan las fusiones transnacionales para concentrar en pocas manos el control de la producción de bienes culturales que es, además de fuente de riqueza, vehículo de transmisión de ideas, en el caso cubano, paralelamente al monopolio estatal sobre los medios de comunicación y las agencias culturales, el paquete controla el mercado informal del entretenimiento. Su oferta, que si bien se presenta como alternativa a los medios estatales, no lo es ante la oferta global de contenidos de entretenimiento, se consolida desde ese espacio subterráneo del que emana su gestión como emisor. El paquete hoy, como antes otros modos de consumo informal de entretenimiento en Cuba, impulsa la homogeneización del consumo cultural que tiene lugar a escala global.

El paquete se inserta en la producción y distribución de contenidos culturales a través de procesos de producción mercantil que se combinan y son atravesados por otros procesos vinculados a ilegalidades (piratería, desvío de recursos, corrupción, mercado subterráneo de productos culturales), 
pero también a prácticas para compartir contenidos y tecnología. Las matrices gestionan los contenidos, la estructura y el precio del paquete, dando lugar a un producto-proceso con valor de uso y valor de cambio. Un compendio altamente demandado y consumido en el país, cuyo costo también se negocia en un espacio del mercado nacional que, aunque se mueve en un entorno subterráneo y no regulado por el Estado, se ve impactado por disposiciones oficiales.

Un ejemplo de esto es el ordenamiento económico que entró en vigor el 1. ${ }^{\circ}$ de enero de 2021 y que, entre otras medidas, elevó hasta en cinco veces el salario mínimo y aumentó los precios oficiales de los productos entre tres y diez veces; el paquete subió inmediatamente su precio de 125 a 150 CUP. El aumento de 25 pesos, equivalente a un dólar estadounidense, representa un incremento del $16 \%$ de su precio.

Aunque el negocio del paquete se inspira en la racionalidad del mercado, no todas las relaciones sociales que se combinan en su fase de circulación se subordinan a la relación mercantil, sino que se combinan muchas otras formas de relaciones, fundamentalmente colaborativas. Esto se conecta con lo planteado por García Canclini (1995) acerca de las mutaciones de los objetos debido a los usos que hacemos de ellos y el significado que les otorgamos:

En cierta fase pueden ser "candidatos a mercancías", en otra pasan por una etapa propiamente mercantil y luego pueden perder ese carácter y ganar otro (...). Estas biografías cambiantes de las cosas y los mensajes conducen a pensar el carácter mercantil de los bienes como oportunidades y riesgos de su desempeño (1995, pp. 54-54).

Con el paquete cubano encontramos que, aunque su origen es mercantil, puede cambiar en sus usos y en los resultados alternos que de estos se deriven: procesos de sociabilidad en el contexto físico y virtual; espacios de libertad desde el consumo que podrían repercutir en otros ámbitos; reflexividad acerca de la autonomía individual; inserción en los flujos globales de consumo cultural; diversificación de referentes; incorporación de prácticas para reproducir y compartir medios digitales que multiplican el acceso a contenidos y a las nuevas tecnologías.

Mosco (2006) afirma que es útil situar a la economía política de la comunicación en oposición a los estudios culturales, por un lado, y la ciencia política, por otro; pero al mismo tiempo propone la necesidad de trabajar la EPC en relación con las disciplinas en su frontera. Eso es justamente lo que proponemos para el abordaje del paquete semanal, un fenómeno que debe ser analizado desde el cruce de sus implicaciones en lo político, lo 
cultural, lo simbólico y lo social. Entre las potencialidades del fenómeno del paquete hay que ubicar, con optimismo, las nociones que puedan derivarse de participar de sus redes de circulación y consumo, por ejemplo, acerca de la autonomía individual frente al Estado. Esto podría indagarse en una investigación sobre la reflexividad de los actores en ese sentido.

El caso del paquete corrobora que desde los márgenes institucionales y legales en Cuba es desde donde se están generando los más dinámicos procesos de participación ciudadana y los espacios de reivindicación de libertades. A la participación de los procesos vinculados a la distribución y el consumo del paquete semanal, que tiene lugar en el ámbito del consumo, debemos agregar la labor del periodismo independiente y el activismo defensor de derechos humanos, que sí se insertan directamente en lo público y lo político como formas frontales de enfrentamiento al poder. El caso del paquete nos permite acercarnos al entorno de lo privado para explorar cómo se experimenta en este espacio la noción de libertad frente al poder, también desde prácticas ilegales, aunque no criminalizadas ni perseguidas.

A través del paquete como negocio se legitima, porvías no institucionalizadas, pero ampliamente socializadas, el poder de la mediación del mercado en la producción, distribución y consumo mediático, lo que implica al mismo tiempo una homogeneización del consumo acorde a las tendencias globales, y su estructura también reproduce en el contexto cubano una concentración de la producción y la distribución, libre, además, de toda fiscalización del Estado. Sin embargo, y a diferencia de las industrias culturales tradicionales, en la estructura de red del paquete, después de los dos o tres primeros niveles comienzan a producirse múltiples interacciones y prácticas, y a generarse diversas significaciones en torno a estos procesos. Este panorama invita a considerar el análisis del paquete teniendo en cuenta las interacciones entre las lógicas de producción y las lógicas de los usos, de modo que podamos atender al sistema de relaciones que se establece entre productores y consumidores. Estas relaciones forman parte de la producción y el consumo cultural en Cuba hoy, y se configuran entre las ofertas estatales y las informales.

\section{Referencias}

Barrera, Y. (2009). La revuelta del espectador: estudio exploratorio sobre el consumo mediático alternativo [Tesis de maestría inédita]. Universidad de La Habana.

Cabrera, C. (2015). Rutas USB. Acercamiento a la gestión de contenidos audiovisuales en el formato Paquete que realizan actores no institucionales en redes informales en La Habana [Tesis de licenciatura inédita]. Universidad de La Habana. 
Celecia, C. (2019). Ciudadanía contestataria en Cuba: un examen desde la comunicación pública (pp. 14-20). En M. Sánchez, Diversidad y desarrollo social. Pearson.

Cogo, D. (2011). Los Estudios de Recepción en América Latina: perspectivas teóricometodológicas [PDF]. Portal Comunicación. https://incom.uab.cat/portalcom/wpcontent/uploads/2020/01/48_esp.pdf

Concepción, J. R. (2015). La cultura empaquetada. Análisis del consumo audiovisual informal del paquete semanal en un grupo de jóvenes capitalinos [Tesis de licenciatura inédita]. Universidad de La Habana.

Díaz, A. (2014). Mirada al Programa de Comunicación Popular del Centro Martin Luther King desde la concepción de las industrias [Tesis de licenciatura inédita]. Universidad de La Habana.

Durán, M. (2015). El realismo mágico de la pantalla chica. Características de la Televisión Cubana como industria cultural [Tesis de licenciatura inédita]. Universidad de La Habana.

Dye, M., Nemer, D., Mangiameli, J., Bruckman, A., y Kumar, N. (2018). El paquete semanal: The Week's Internet in Havana. Actas de la Conferencia CHI 2018 sobre Factores Humanos en Sistemas de Computación (CHI '18), Nueva York.

Fazekas, D. y Marshall, S. (2016, marzo 21). The package (el paquete) is illegal but it's Cuba's number one employer. ABC News. https://abcnews.go.com/International/package-elpaquete-illegal-cubas-number-employer/ story? id=33279812

Fonseca, D. y Castañeda, D. (2015). Teleadictos: conquistando la TV por la izquierda. Aproximación a la construcción de sentidos a partir del consumo mediático informal de programas audiovisuales en el asentamiento precario San Pablo en Santiago de Cuba. Alcance, 4(7), 64-88.

Garcés, G. (2015). Dial entre cultura y economía. La radio cubana desde el enfoque de las industrias culturales [Tesis de licenciatura inédita]. Universidad de La Habana.

García, N. (1995). Consumidores y ciudadanos. Conflictos multiculturales de la globalización. Editorial Grijalbo.

García Canclini, N. (2002). Las industrias culturales y el desarrollo de los países americanos. Organización de Estados Americanos.

García, T. (2018). La producción cultural como fuerza productiva directa en Cuba. Algunas notas (pp. 161-172). En J. Sánchez, S. Arroyo, J. Parra y A. Verdú (Coords.), Las industrias culturales y creativas en Iberoamérica, evolución y perspectivas. Tadigra.

Laguardia, J. (2012a). Economía de la cultura e industrias culturales: su comprensión desde la economía política. Tensiones Mundiales, 129-149.

Laguardia, J. (2012b). ¿Industrias culturales o creativas? Notas sobre economía de la cultura. Temas, 72, 28-37.

Lobato, R. (2012). Shadow economies of cinema: mapping informal film distribution. Palgrave Macmillan / BFI.

Martín-Barbero, J. (2003). De los medios a las mediaciones. Bogotá: Convenio Andrés Bello. Martínez, Y. (2008). En busca de fisonomías de receptores para productores de televisión en Cuba [PDF]. Perfiles de la Cultura Cubana, (1), 1-10. http:/ / www.perfiles.cult.cu/ articulos/busca_fisonomias.pdf 
Martínez, P. (2015). Turismo de reuniones: entre el recelo y el realismo mágico [Tesis de licenciatura inédita]. Universidad de La Habana.

Miège, B. (2006). La concentración en las industrias culturales y mediáticas (ICM) y los cambios en los contenidos. CIC, Cuadernos de Información y Comunicación, 11, 155-166. Recuperado de https:// revistas.ucm.es/index.php/CIYC/article/view/CIYC0606110155A

Mosco, V. (2006). La Economía Política de la Comunicación: una actualización diez años después. CIC, Cuadernos de Información y Comunicación, 11, 57-79. Recuperado de https:// revistas.ucm.es/index.php/CIYC/article/view/CIYC0606110057A

Murdock, G. (2006a). Bajo la playa, los adoquines: Mercancías, Consumismo, Contradicciones. CIC. Cuadernos De Información Y Comunicación, 11, 31 - 46. Recuperado de https:// revistas.ucm.es/index.php/CIYC/article/view/CIYC0606110031A

Murdock, G. (2006b). Los agujeros negros del marxismo occidental: Respuesta a Dallas Smythe. CIC. Cuadernos De Información Y Comunicación, 11, 11 - 22. Recuperado de https:// revistas.ucm.es/index.php/CIYC/article/view/CIYC0606110011A

Oro. H. (2015). Arte e Industria. Caracterización del Instituto Cubano de Arte e Industria Cinematográfico (ICAIC) como una industria cultural. [Tesis de licenciatura inédita]. Universidad de La Habana.

Orozco, G. (2009). Mediaciones tecnológicas y des-ordenamientos comunicacionales. México.

Ramos, A. (2016). Alternativas Un acercamiento a las principales características del proceso de gestión editorial de revistas temáticas, distribuidas mediante el Paquete Semanal. [Tesis de licenciatura inédita]. Universidad de La Habana.

Pertierra, A. C. (2011). Placeres privados. La Gaceta de Cuba, 5, 17-22.

Pertierra, A. C. (2012). If they show Prison Break in the United States on a Wednesday, by Thursday it is here: mobile media networks in Twenty-First-Century Cuba. Television e New Media, 13(5), 399-414.

Players G. (enero-junio de 2017). Los movimientos de las plazas en el decenio 2010. Más allá de los nuevos movimientos sociales. Revista Mexicana de Estudios de los Movimientos Sociales. 1, 80-105.

Players, G. (2018). La vía de la subjetividad: experiencia vivida, autonomía y creatividad. En G. Players (Coomp.), Movimientos sociales en el siglo XXI. Perspectivas y herramientas analíticas (pp.55-78). Buenos Aires: CLACSO.

Rodríguez, F. A. (2019). Círculos infinitos: repensar las prácticas de circulación no institucional de contenidos audiovisuales en redes digitales en Cuba. En M. Oller, D. Olivera y A. Somohano (Eds.), En Cuba periodismo es más (+): transposición, redundancia y dinamismo profesional (205-230). Sociedad Latina de Comunicación Social.

Rojas, J.; Carballo, J.A. (2018). Consideraciones sobre la distribución espacial de los emprendimientos culturales. Reflexiones para el debate en clave cubana. CariCen. 65-77. Sánchez, E. (2006). Industrias culturales, diversidad y pluralismo en América Latina. CIC, Cuadernos de Información y Comunicación, 11, 207-221. https:// revistas.ucm.es/index. php/CIYC/article/view/CIYC0606110207A 